\title{
Entre la modernidad y la preservación de la memoria: las ilustraciones del artista catalán Francisco Fortuny (1864-1942) en las revistas de Buenos Aires ${ }^{1}$
}

\author{
Irene Gras Valero \\ Universitat de Barcelona \\ igrasv@ub.edu \\ Artículo bajo licencia Creative Commons \\ Atribución 4.0 Internacional (CC BY 4.0) \\ ENVIADO: 2019-07-10 \\ ACEPTADO: 2019-11-20
}

\section{RESUMEN}

El presente artículo se centra en la producción gráfica del artista catalán Francisco Fortuny Masagué, dentro del ámbito de los magazines y semanarios ilustrados de Buenos Aires de finales del siglo XIX y principios del siglo XX. Fortuny emigró a Argentina en 1887 y terminó residiendo en dicho país hasta su muerte A nivel iconográfico constataremos como Fortuny recrea, por una parte, un imaginario urbano y social vinculado a la modernidad de una metrópoli en pleno desarrollo. Y por otra, como participa en la elaboración de imágenes didácticas que conectan con el pasado histórico y aspiran a impulsar el nacionalismo.

PALABRAS CLAVES

Francisco Fortuny Masagué, ilustración gráfica, imaginarios visuales, Argentina, revistas.

\section{RESUMO}

0 presente artigo centraliza-se na produção gráfica do artista catalão Francisco Fortuny Masagué, no âmbito das revistas e jornais semanais ilustrados de Buenos Aires do princípio do século XX. Fortuny emigrou para Argentina em 1987, e acabou residindo naquele país até a sua morte. Em um nível iconográfico, iremos constatar como Fortuny recria, por uma parte um imaginário urbano e social vinculado a modernidade de uma metrópole em pleno desenvolvimento. E por outra, como participa na elaboração de imagens didáticas que se conectam com o passado histórico e aspiram impulsionar o nacionalismo.

PALAVRAS-CHAVE

Francisco Fortuny Masagué, ilustração gráfica, imaginário, Argentina, revistas

\section{ABSTRACT}

This paper focuses on the graphic production that the Catalan artist Francisco Fortuny Masagué developed for early 2oth century magazines of Buenos Aires. Fortuny migrated to Argentina in 1887 and lived there up to his death. On an iconographic level, we will show that Fortuny pictured, on one hand, an urban and social imaginary related to the modernity of a developing metropolis. On the other hand, he took part in the making of didactic images connecting with the historical past and aspiring to foster nationalist ideologies.

KEYWORDS

Francisco Fortuny Masagué, graphic illustration, visual imaginaries, Argentina, magazines. 


\section{INTRODUCCIÓN}

Francisco Fortuny Masagué (Tarragona, 1864 - Buenos Aires, 1942) fue en verdad un artista multifacético y prolífico, que además desarrolló su trayectoria profesional en Buenos Aires, lejos pues de su país natal. Este hecho no comportaba ninguna novedad. El fenómeno de la inmigración argentina, impulsado por los gobiernos liberales, resultó especialmente notable entre los años 1880 y 1930 (Garabedian, 2012: 159-163). Además de abundante mano de obra, también llegaron a las costas del Río de la Plata numerosos artistas, literatos e intelectuales, procedentes principalmente de Italia y de España (Gutiérrez, 1997: 113). A propósito del ámbito de la ilustración, según relata uno de los cronistas de la revista Papel y Tinta, revista en la cual colaboró el propio Fortuny: "Los dibujantes españoles son legión hoy en Buenos Aires, y es necesario consignar en su elogio que la febril vida comercial de esta metrópoli no es el medio más apropiado para estos mágicos del lápiz" (Papel y Tinta, 1908: 3). Y en esa legión destacaron varios nombres: además del propio Fortuny, el de Mayol, Cao, Villalobos y Vaamonte, los cuales hicieron gala de un caricaturismo sarcástico y crítico. Cabe añadir que la mayoría de ellos compaginaron su labor ilustradora con la pintura (Fernández-García, 1997: 64). De ahí, como decíamos, el carácter polifacético de Fortuny. Durante su etapa porteña, éste se consagró a la creación de imágenes artísticas relacionadas con la historia y el carácter nacional argentinos, pintado escenas relevantes del pasado patrio como encargos públicos y privados e ilustrando a su vez libros pedagógicos de historia, como los de Mariano A. Pelliza o Alfredo B. Grosso. ${ }^{2}$ Sin embargo, en el presente artículo únicamente nos centraremos en su trayectoria como dibujante de revistas, dada su extensa y notable producción en publicaciones como: El Sud-Americano, Buenos Aires, Caras y caretas, Pulgarcito, PBT, La Vida moderna, Papel y tinta, Plus Ultra, Iris, Billiken, Fray Mocho, Vida Porteña, Catalunya al Plata, El Gladiador, Cascabel o Mundo argentino. ${ }^{3}$ Cabe añadir que buena parte de éstas recogen el legado dejado por la prensa satírico-burlesca de mediados del siglo XIX, caracterizada por el uso de la caricatura y de una retórica mordaz de ánimos combativos (Ojeda, Moya y Sujatovich, 2018: 434; Román, 2010: 18-21). A raíz de ello Fortuny obtuvo un gran reconocimiento, hasta el punto de ser considerado "el decano de los ilustradores de la Argentina” (La Nación, 1964). "A él acuden (...) los directores de revistas y obras literarias en busca de la alegoría, de la nota de actualidad, que traza Fortuny con tanta verdad como intención, con tanta precisión como rapidez" (Otaegui, 1897: 14).

2 Sobre este tema véase: Rodríguez-Samaniego, C., Ilustrar la historia nacional: el dibujante Francisco Fortuny (1864-1934) y los libros escolares en la Argentina del Centenario (artículo pendiente de publicación).

3 Dejaremos aquí también de lado su colaboración en numerosos periódicos, tales como La prensa, La Nación, La razón, La época, El Diario español, El Correo de Galicia, La Tarde o El Correo Español, buena parte de ellos pertenecientes a la prensa inmigrante española publicada en la Argentina (Rodríguez, 1928: 10). 
Fortuny también recibiría clases de Copia de Estampa, hecho que le beneficiaría en su trabajo como diseñador de patrones en una fábrica de tejidos del barrio de Sants.

El 1885 tenemos constancia de que participa con dos óleos en la Primera Exposición de acuarelas, dibujos, pinturas al óleo y escultura, celebrada por el Centro de Acuarelistas de Barcelona en el Museo Martorell (Catálogo General ilustrado, 1885). Y entre 1886 y 1888, como decíamos, ejerce como ilustrador de diversas revistas catalanas, una de ellas, la llustración, de carácter "hispano-americano". ¿Puede que este hecho le reportará contactos adecuados que le facilitaran su traslado a Buenos Aires? ¿tenía pensado, desde un principio, quedarse en la capital argentina hasta el final de sus días? ¿cuáles fueron exactamente los motivos que lo impulsaron a emigrar hasta allí, más allá de la demanda de artistas y mano de obra? Nos resulta imposible, por el momento, dar respuesta a todas estas cuestiones, sin embargo, consideramos importante por lo menos plantearlas...

El joven Fortuny llegó a Buenos Aires un 24 de diciembre 1887, a bordo del barco Pelayo. ${ }^{4}$ En su tierra natal, Cataluña, ya hacía un par de años que ejercía como ilustrador de revistas: en La llustració Catalana (1880-1894) y en La llustración. Revista hispano-americana (1880-1890). ${ }^{5}$ En ambas abordó temas diversos: el paisaje, obras de carácter costumbrista y social, la historia... Todas las ilustraciones llevan su firma -F. Fortuny Maseguer ${ }^{6}$, y algunas vienen acompañadas de un breve descriptivo que incorpora una valoración de su estilo. ${ }^{7}$ En una de ellas, por ejemplo, se afirma que "La composició está ben disposada y revela en son autor un talent no comú, que li portará, sens dubte, un brillant pervenir" (Nostres grabats...1886: 386). ${ }^{8}$

Hijo de Pere Fortuny i de Antònia Masagué, Francisco Fortuny nació en la Pobla de Montornès (Tarragona) un dos de enero de 1864 (Libro de bautismos de la Pobla de Montornès, 18721866: 166)..$^{9}$ Con tan sólo con ocho años sin embargo se trasladó a Barcelona, debido a su delicada situación familiar ( $L a$ Nación, 1964). En 1879 ya pudo iniciar su formación artística en la escuela de la Lonja de Barcelona - hecho que no recoge ninguna de sus biografías ${ }^{10}$ - donde cursaría Estudios de Artes Aplicadas hasta el año 1881, y Estudios Superiores de pintura, escultura y grabado hasta 1883 (Libro de Matrícula...). Estos datos nos permiten constatar que Fortuny iniciaría su aprendizaje con una finalidad más bien práctica, de carácter artesanal, para luego acabar formándose en las bellas artes - proceso, por otro lado, común en muchos artistas- hecho que repercutiría en su trayectoria artística. Además de matricularse en asignaturas como Paisaje, Perspectiva, Anatomía o Dibujo del antiguo,

\footnotetext{
$4 \quad$ Base de datos del CEMLA.

5 A partir de ahora, al hacer mención por primera vez de una revista, se especificarán, entre paréntesis, el primer año y el último de su publicación. Ello no implica que Fortuny colaborase en dicha revista durante todo ese periodo; normalmente lo hacía durante alguna etapa, más o menos larga, dependiendo de cada caso.

$6 \quad$ Pese a que en el Libro de bautismos de la Pobla de Montornès (véase a continuación) aparece como segundo apellido "Masagué", en ambas revistas Fortuny firma "F. Fortuny Maseguer". en Argentina

Fortuny continuó colaborando en La llustración Catalana estando ya

8 “La composición está bien dispuesta y revela en su autor un talento
} no común, que lo conducirá sin duda a un brillante futuro" (traducción propia).

9 El hallazgo de estos datos ha permitido desmentir la fecha de nacimiento que apuntaban las biografías relativas a Fortuny: 1865. Vid: FernándezGarcía, 1997: 241; La Nación, 1964; Francisco Fortuny, 2004.; Gesualdo et al., 1969; Huguet, 1956: 22; Páez de la Torre, 2017 o Rodríguez, 1928: 9.

10 La mayor parte de sus biógrafos omiten, como hemos señalado, los estudios cursados en Barcelona, y únicamente hacen referencia, de manera errónea, a la formación artística recibida por Fortuny en la Real Academia de San Fernando de Madrid.

En Argentina Fortuny supo integrarse muy bien en el ambiente cultural de la época. Además de dedicarse al ámbito de la ilustración gráfica (tanto en lo que concierne a las revistas, como a los libros escolares), también recibió encargos de carácter pictórico, donde cultivó especialmente el género retratístico y los temas de historia. ${ }^{11}$ Por otra parte, el artista participó en diversos certámenes artísticos a lo largo de su trayectoria, como por ejemplo en la Tercera Exposición del Ateneo, celebrada el 20 de octubre de 1895, donde se exhibieron varios de sus óleos. 0 en la Exposición de Bellas Artes y Artes Aplicadas de la Colmena Artística, organizada en $1897 .{ }^{12}$ Laura Malosetti consigna estos hechos y sitúa a Fortuny entre Los primeros modernos (2002: 377). que sería publicada en la portada del n. 115 de la Revue Illustree du Rio de la Plata (reproducida en Malosetti, 2002: s/p.). 


\section{VISIONES DE LA METRÓPOLI, IMÁGENES DE LA MODERNIDAD}

A su llegada a Buenos Aires, Fortuny se topó con una situación difícil: una ciudad en desarrollo, pero con numerosos conflictos internos. Eran "los tiempos de los pasmosos negocios de especulación desenfrenada, de la intensísima lucha política que desembocará en las sangrientas jornadas de julio de 1890 (...) los tiempos de los dolores del crecimiento, súbito y desmesurado, de un país nuevo" (Huguet, 1956: 22). Sin embargo rápidamente obtendría un empleo en los talleres gráficos de "La Prensa” y en la Compañía Sudamericana de Billetes de Banco. Ésta última, además de dedicarse a la impresión de billetes, sellos postales, etc, también producía obras de carácter literario, científico e histórico (vid: Matassi, 2018) ${ }^{13}$, como por ejemplo la revista El Sud-Americano (1888-1891), en la cual Fortuny participó como ilustrador entre 1889 y 1891.

Éste sin duda, constituye uno de los periódicos culturales más ilustrados de la prensa argentina del siglo XIX. Con un estilo similar al plasmado en las publicaciones catalanas, pero con una producción mucho más amplia, el artista reprodujo edificios públicos y privados, infraestructuras, paisajes, retratos de personalidades, episodios históricos, escenas costumbristas... a la par que ilustraba noticias de sucesos e incluso novelas por fascículos. ${ }^{14}$ Sus dibujos, pues, pasaron de estar desvinculados del texto a integrarse en composiciones literarias específicas, hecho que se repetiría en numerosas revistas. Sin embargo sería en El Sud-Americano donde Fortuny participaría de una verdadera "narrativa del progreso", dadas las preferencias iconográficas de la revista: "representaciones de vistas rurales y urbanas, edificios destacados, lugares en su mayoría argentinos o americanos y algunos pocos del resto del mundo, muchas muestran un contexto en construcción, de edificios monumentales, ferrocarriles y urbanizaciones, pero con sus espacios agrícolas pujantes y productivos, básicos sostenes de la riqueza material" (Szir, 2017). Lo mismo sucedería en una de las más destacadas revistas de Buenos Aires de la primera mitad del siglo XX: Caras y Caretas (1898-1939). Ésta se convirtió en el primer periódico ilustrado que conseguiría llegar al público masivamente en muy poco tiempo, instituyendo unas nuevas pautas de comunicación visual. ${ }^{15}$ Ambas publicaciones se nutren de noticias de actualidad y muestran, a través de la configuración de un imaginario urbano, ${ }^{16}$ el progreso material de la nueva metrópoli, hasta el punto de ayudarnos a "historiar" dichas transformaciones. ${ }^{17}$

Fortuny participa en la elaboración de dicho imaginario, representando, por ejemplo, las vistas de Puerto Madero, a raíz de la inauguración de su dársena sur el 28 de enero de $1889 .{ }^{18}$

13 Según consta en un aviso gráfico del mismo periódico, la Compañía publicitaba "Grabados sobre acero, cobre, zinc, madera, etc. Litografía, Imprenta, Encuadernación, Fábrica de Libros en Blanco, Fototipía, Estereotipía. Fundición de Tipos, Billetes de Banco, Títulos de renta, Retratos, Cheques" (SZIR, 2014: 90).

14 Según se detallaba en los epígrafes de la propia revista, las imágenes estaban tomadas " del natural” por sus enviados.

15 "Integró, por medio del uso de las imágenes, la actualidad y la publicidad ilustradas, la espectacularización de la vida cotidiana, pero también desarrolló todo tipo de géneros textuales” (Szir, 2010: 473).

16 Sobre el tema del imaginario urbano de Buenos Aires a principios del siglo XX, véase: Gutman y Reese, 1999.

17 Sobre el tema del desarrollo urbanístico de Buenos Aires, véase: Bonelli, 2017; Szir, 2010 y Gorelik, 2004.

18 Fortuny, F. (15 de febrero-1889), El Puerto Madero. Ilustración de El Sud-Americano, n. 14.
También tiene algunas ilustraciones que nos muestran la modernidad tecnológica que suponía el ferrocarril como medio de locomoción. ${ }^{19}$ En las páginas de un ejemplar de El Sud-Americano de 1889, por ejemplo, podemos observar el paso del tren y diversas de las instalaciones ferroviarias, ${ }^{20}$ para conmemorar el aniversario de la inauguración del ferrocarril en Buenos Aires el 30 de agosto de 1857. La misma revista, sin embargo, también nos ofrece la vista de un suceso de actualidad que supone la otra cara del progreso: un accidente de tren producido en la línea ferroviaria que conecta Buenos Aires con Rosario. ${ }^{21}$ La estética realista y minuciosa, casi fotográfica, que había empleado Fortuny en ambos casos, contrasta con la ilustración reproducida a modo de caricatura en Caras y Caretas el 1901. Bajo el título "La locomoción en el siglo XX", el artista nos muestra una especie de carrera donde participan, además del tren, el tranvía, la bicicleta y el coche...tomando la delantera a los antiguos y desfasados carruajes (Fig. 1).

Otras imágenes, a modo de noticias de actualidad, nos permiten constatar los problemas que sufría la metrópoli a raíz de accidentes, incendios, o de catástrofes naturales, como las grandes inundaciones que anegaban las calles. ${ }^{22}$ En otra caricatura publicada en Caras y Caretas el 1900, Fortuny hace un compendio de ellas bajo el título "Las pestes del año". Situada en el centro de la composición, la muerte armada con su tradicional hoz va sembrando por doquier varios infortunios: "insolaciones", “pestes”, “inundaciones” y "la revolución”, representadas en una especie de viñetas laterales. ${ }^{23}$

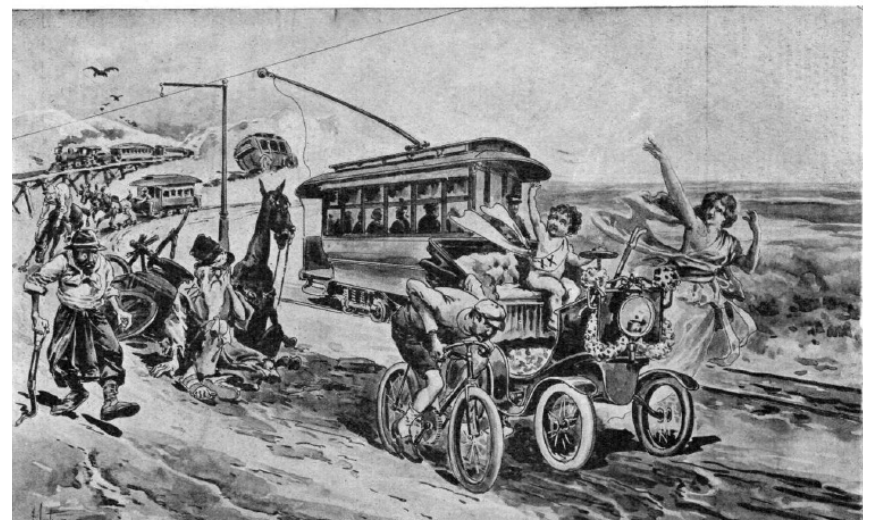

Fig. 1 / Francisco Fortuny (5 de enero -1901). La locomoción en el siglo XX. Ilustración de Caras y Caretas, n. 118, 43.

Por otro lado, a la hora de configurar este escenario de modernidad a modo de paisaje visual, el artista también reproduce minuciosamente instalaciones y edificios de carácter público y privado, especialmente desde las páginas de la revista $E l$ Sud-Americano. Allí podemos observar, a modo de ejemplo, la representación de uno de los primeros parques de diversión de Buenos Aires, donde se jugaba a pelota y se celebraban conciertos: el Frontón Nacional ${ }^{24}$ (vid: Cecchi , 2012: 46), o bien el suntuoso edificio, de reminiscencias francesas, perteneciente

\footnotetext{
19 Sobre el tema, véase: Bonelli, 2017: 118-120.

20 Fortuny, F. (5 de septiembre- 1889). Ilustración de El Sud-Americano, ก. 28.

Fortuny, F. (20 de marzo- 1889). Ilustración de El Sud-Americano, n. 17. 22 Veáse por ejemplo: Fortuny, F. (5 de febrero -1889). El último temporal. Ilustración de El Sud-Americano, n. 14.

23 Fortuny, F. (5 de mayo -1900). Ilustración de Caras y Caretas, n. 83, 18. 24 Fortuny, F. (5 de febrero -1889). Ilustración de El Sud-Americano, n. 14
} 
al político Torcuato de Alvear. ${ }^{25}$ El edificio del Palacio del Gobierno de Argentina -actual Casa Rosada-, inaugurado en 1898 en la calle Balcarce 50, también adquiere importancia como telón de fondo de un acontecimiento histórico: la "Recepción del presidente de la República Oriental. Desfile de tropas frente al Palacio del Gobierno".

En última instancia, cabe tener en cuenta que este tipo de edificios y de instalaciones, registrados bajo el prisma de lo moderno "participan de una visualidad ligada a ciertos intereses institucionales e ideológicos compartidos con las obras de paisaje canónicas que, ya en el siglo XX, definirán la dupla de “paisaje-identidad nacional”" (Bonelli, 2017: 115). De hecho, la misma configuración urbanística de Buenos Aires tiene como modelo a referentes europeos, a fin de distinguirse del resto de ciudades latinoamericanas. Se trataba pues de acentuar su singularidad en la construcción visual de la identidad nacional, aunque esta última, como veremos, sea del todo compleja y heterogénea.

Cabe apuntar que esta "transculturalidad" reflejada a nivel urbanístico, también se manifiesta en el carácter de las propias revistas: buena parte de los magazines y semanarios de Buenos Aires de principios del siglo XX tenían como referencia la prensa ilustrada americana y europea. ${ }^{26}$ Se trataba, en aras de la modernidad, de apropiarse de formas visuales y conceptuales foráneas, aunque ello significara confrontarse a la idea de lo local o nacional (Szir, 2017). Dicha transculturalidad en el ámbito gráfico, además, permite explicar el éxodo migratorio de dibujantes españoles y de otros países europeos, como el propio Fortuny (Fernández-García, 1997: 64) fenómeno que ya señalábamos al principio del artículo.

Por otra parte, para finalizar este apartado, hay que tener en cuenta que la modernidad a la que aspiraban dichas revistas no solamente se reflejaba en la configuración de un determinado imaginario urbano, como hemos visto, sino también en la elección de una estética visual, vinculada al art nouveau y al art déco, que les permitirá participar en las corrientes artísticas que se encontraban plenamente en boga (Fernández, López y Petris, 1999: 245)

\section{LAS CONTRADICCIONES Y COMPLEJIDADES SOCIALES DEL PROGRESO}

Dentro de este escenario urbano, Fortuny también representará a sus protagonistas, es decir, a los actores sociales. Y en este sentido, pondrá de manifiesto los contrastes de la sociedad argentina del momento. De hecho, buena parte de las revistas en las que el artista colaborará manifestarán este tipo de desigualdades, como es el caso del semanario Fray Mocho (1912-1929): "Las páginas de la revista dejan ver esta realidad de transición. Se ven los trajes y las fiestas de la aristocracia, las grandes tiendas, la política, pero también las criadas y los mozos en el parque, los niños que trabajan en las fábricas, los vagabundos, los obreros del suburbio" (Piñeiro y Sotolano, 2001: 271). Algunas de las imágenes descritas por Fortuny muestran así las actividades y pasatiempos de las clases acomodadas. Engalanadas con sus mejores trajes de corte europeo, las veremos celebrar los Carnavales por las calles de la ciudad, ${ }^{27}$ consumir licores en cafés y restaurantes (fig. 2) o relajarse charlando en interiores suntuosos. ${ }^{28}$

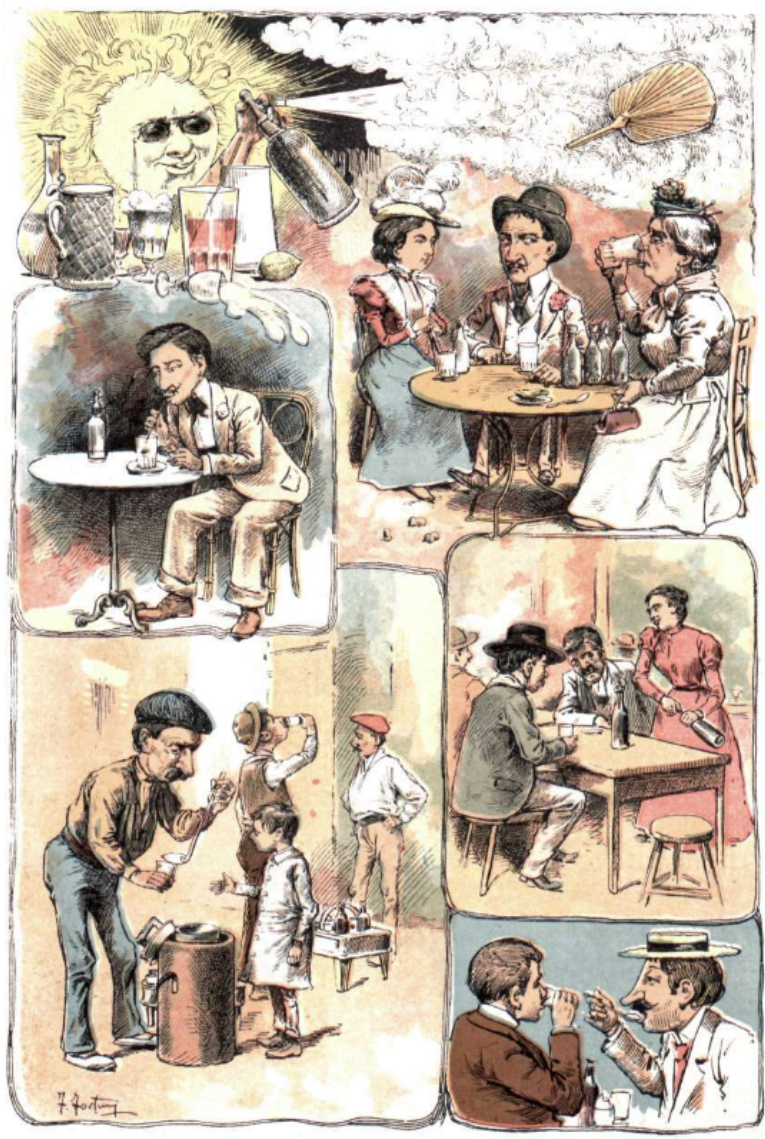

Fig. 2 / Francisco Fortuny (30 de diciembre -1899). Actualidad líquida. Ilustración a color de Caras y Caretas, n. 65, 20.

Pero este tipo de escenas no serán las predominantes en la iconografía cultivada por el artista. Éste sobre todo dedicará su atención a las clases más desfavorecidas, especialmente a las pertenecientes al ámbito rural. Sin duda el proceso de desarrollo urbanístico no había hecho desaparecer aún de las calles las zonas más agrestes. Por tanto, junto a los espacios y edificios

\footnotetext{
27 Fortuny, F. (11 de febrero -1899). Ilustración de Caras y Caretas, n. 19,15 o Fortuny, F. (23 de febrero -1907). Ilustración de PBT, n. 119.

$\begin{array}{ll}28 & \text { Fortuny, F. (febrero -1890). Ilustración de El Sud-f } \\ \text { Fortuny, F. (21 de septiembre -1899). Ilustración de Iris n. } 8 .\end{array}$
} 26 Caras y Caretas, por ejemplo, se vinculaba directamente a un modelo de revista americana surgido en 1895 (vid. Garabedian, 2009: 81; Ojeda y Moya, 2018: 427). 
representativos de la modernidad, se seguirán representado los suburbios, los márgenes rurales, e incluso, la pampa (Szir, 2010: 464). De este modo se aúnan la tradición, representada por lo popular, y el progreso o la novedad. Fortuny dará forma pues a escenas de carácter costumbrista, donde adquirirán protagonismo personajes pobres o humildes concentrados en sus quehaceres cotidianos. En las revistas PBT (1904-1918), Fray Mocho, Caras y Caretas o Iris (1899-1900) es donde encontramos una extensa proliferación de este tipo de imágenes, algunas de ellas a color. Podemos ver, por ejemplo, a trabajadores desayunando sobre las calles, ${ }^{29}$ a un "Restaurant ambulante", ${ }^{30}$ a un grupo de mujeres conversando delante de la verja de su casa (Fig. 3), a otras dos desplumando gallinas... ${ }^{31}$

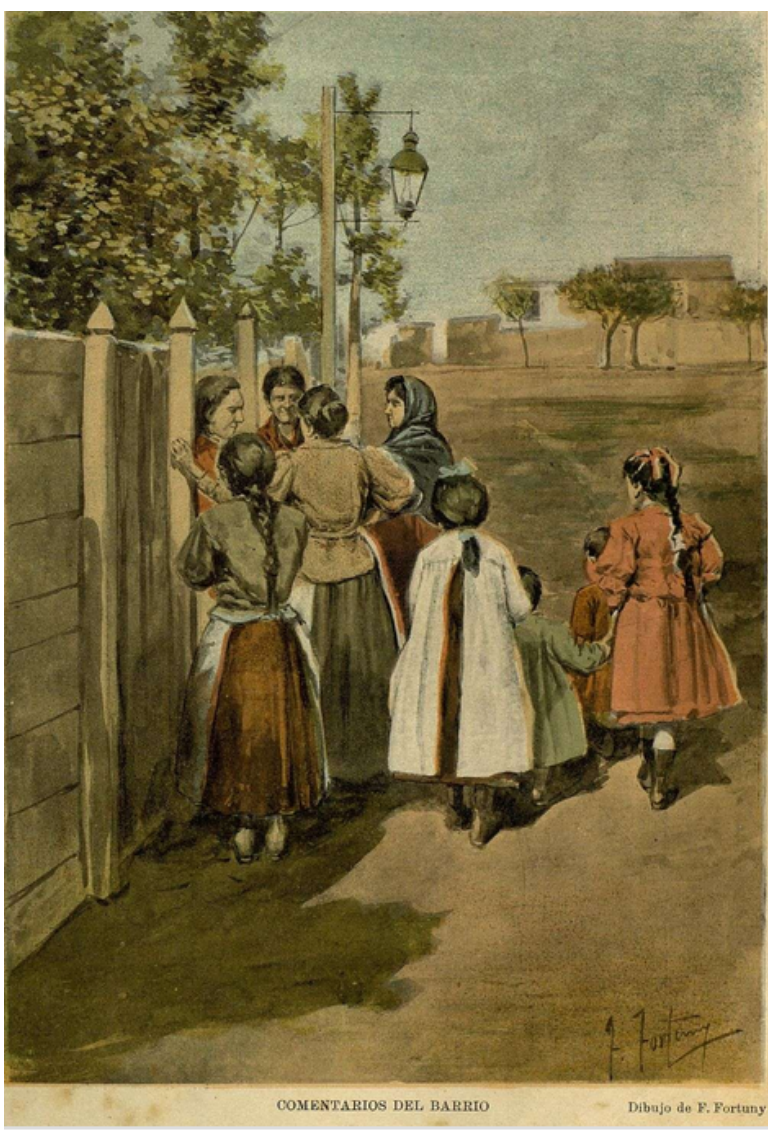

Fig. 3 / Francisco Fortuny (21 de septiembre- 1899). Comentarios de barrio. Ilustración a color de Iris, n. 8.

Muchas de estas escenas son ilustraciones de narraciones costumbristas, tal como vemos en un buen número de ejemplares de la revista PBT entre los años 1904 y 1907. Y en la época fue elogiado por ello: "Fortuny había interpretado inteligentemente la emotividad del drama y hecho paisanos y potros como él sabe hacerlos sorprendiendo, viva, la realidad del documento campesino" (Maciel, 1917: 75).

Por otro lado, y en relación a esta misma temática, Fortuny nos ofrece un amplio repertorio de los llamados Tipos y Paisajes, como era habitual en la época en buena parte de

29 Fortuny, F. (26 de enero -1901). El almuerzo de los empedradores. Ilustración de Caras y Caretas, n. 121, 40.

30 Fortuny, F. (20 de abril -1901). Ilustración de Caras y Caretas, n. 133, 39.

31 Fortuny, F. (31 de agosto -1899). Escenas domésticas. Ilustración de Iris, n. 5 .
Iberoamérica desde 1830. La influencia del Romanticismo en el impulso de los sentimientos nacionalistas resultó de vital importancia para el éxito de este género costumbrista. A su vez cabe destacar que la mayor parte del grabado colonial fue ejecutado por extranjeros residentes, los cuales mostraban "sin pretensiones estéticas, como parte de su oficio, con pupila tal vez un poco externa y distanciada, pero honesta y veraz", fragmentos de la vida colonial" (Rigol). Efectivamente, a lo largo de varios números de Caras y Caretas, entre 1900 y 1902, Fortuny ilustrará algunos de los Tipos y Paisajes de Godofredo Daireaux, que aparecieron publicados en forma de monográfico el 1901 por la editorial Prudent Hnos. y Moetze, y que también se encargó de representar. ${ }^{32}$ Para entender el carácter de este tipo de iconografía, baste con citar al propio Daireaux cuando se dirige al lector en un apartado introductorio. Comparándose con un fotógrafo, explica que:

“...apuntando con el aparato de mi memoria algunos de los tipos que había encontrado en los paisajes pampeanos que habité o recorrí, empecé a sacar vistas (...) Lo que pinté, lector, pertenecerá pronto al pasado, este pasado que tan ligero se nos va y desaparece de nuestra vista, borrándose como en una neblina. La mayor parte de mis recuerdos tienen ya veinte años, y más. ¡Cuántos cambios desde entonces! Por esto mismo, me apuré en juntarlos para poderlos comparar con el presente. Si solo ha tomado este librito, seducido por lo que le pareció contener de ameno, para pasar, entretenido, las largas horas de un viaje, mire, leyéndolo, de cuando en cuando, por la ventanilla del vagón, y verá que la Pampa, por monótona que parezca, no carece de atractivo" (Daireaux, 1901: 5-6).

Pese a ser un extranjero, como Fortuny, Daireaux pronto se enamoraría de la Pampa argentina, y diversas de sus obras literarias - como Los dioses de la Pampa (1902), Fábulas argentinas (1905) o Costumbres criollas (1915)- nos muestran un interés por preservar el folklore y las tradiciones rurales. Por ello, aparte de hablar del "criollo"- nombre con el que en Argentina y otros países se designaba a aquellos nacidos en el continente americano, que eran descendientes de europeos y que acabaron por conformar una élite cultivada propietaria de tierras y negocios- Daireaux también incidirá en la figura del "gaucho". Este término, que hasta finales del siglo XIX poseyó un tinte despectivo, al asimilarse a alguien tosco, ignorante y bruto, en realidad en sus inicios designaba a un habitante seminómada de las llanuras de Argentina y otras regiones, una especie de tipo rural o de peón montado a caballo, que principalmente cazaba ganado silvestre (vid: Rodríguez-Molas, 1982). Fortuny tiene varias ilustraciones dedicadas a la figura ecuestre del gaucho (fig. 4 ), la cual además adquiriría importancia por su vinculación con el nacionalismo, dada su participación en las guerras por la independencia.

32 Fortuny se encaró de ilustrar la Primera y la Segunda Serie. Cabe añadir que las ilustraciones de Caras y Caretas y las del citado monográfico difieren, pese a tratarse del mismo contenido narrativo. 


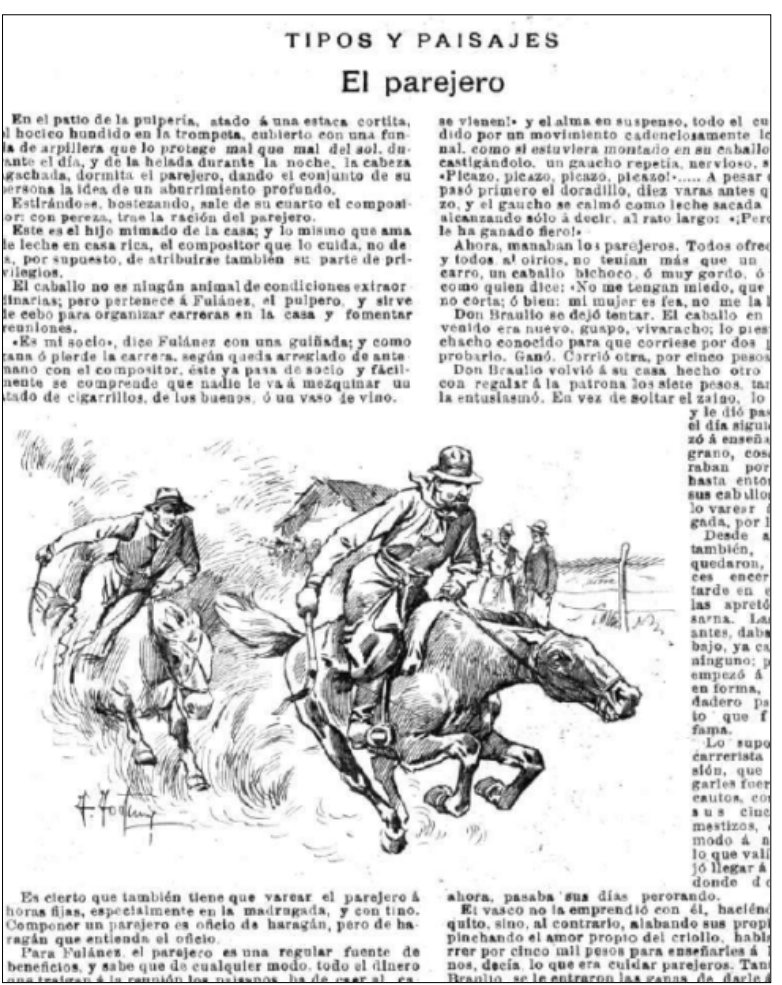

Fig.4 / Francisco Fortuny (9 de noviembre -1901). El parejero. ilustración de Tipos y Paisajes de Godofredo Daireaux, Caras y Caretas, n. 162, 38.

Además del criollo y del gaucho encontramos otro personaje ampliamente representado por Fortuny: el indígena autóctono (fig. 5) $)^{33}$.

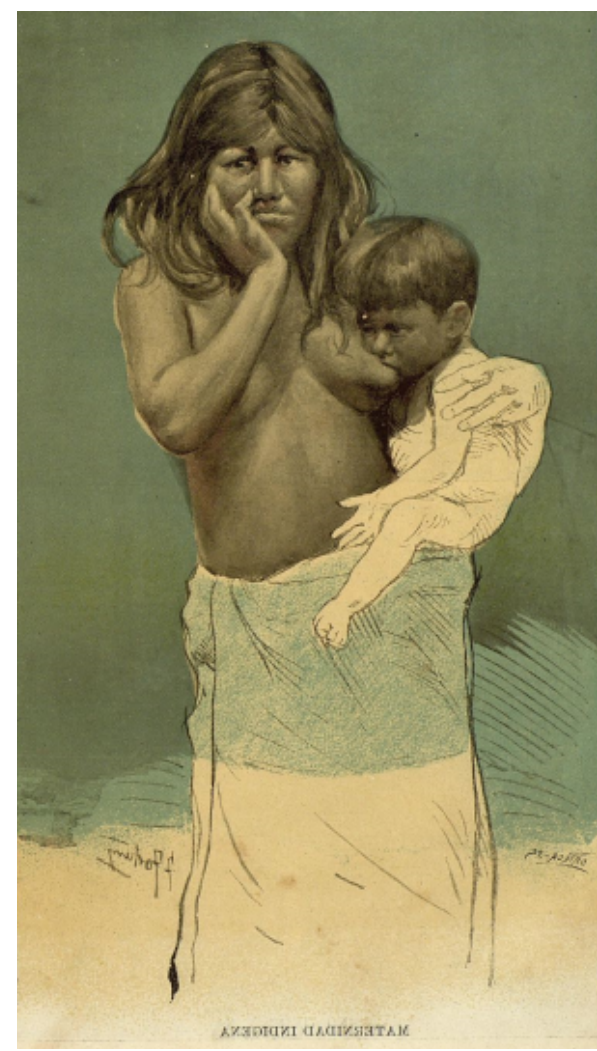

Fig. 5 / Francisco Fortuny (10 de agosto -1899). Maternidad indígena. Ilustración a color de Iris, n. 2.

La misma ilustración será aprovechada por Fortuny para acompañar el texto “Gualicho" de Lucio V. Mansill, publicado en Caras y Caretas, n. 785, 18 de octubre-1913, 50 .
Entre los años 1913 y 1914, el artista catalán ilustró numerosos relatos publicados en Caras y Caretas que relataban sus costumbres. Asimismo, esta figura adquiere protagonismo en las narraciones sobre la conquista española del Rio de la Plata, tal como observamos en las ilustraciones de Fortuny sobre "Los tesoros del Rey Blanco. Episodio romancesco de la conquista del Rio de la Plata", de Roberto J. Payró, publicado en diversas entregas en Caras y Caretas el 1926 y, de manera póstuma, el 1935, por la editorial Sociedad Amigos del Libro Rioplatense.

En definitiva, criollos, gauchos, indígenas...todos ellos conforman una identidad compleja y heterogénea, y ponen de manifiesto las contradicciones y los contrastes de la nueva metrópoli en desarrollo. A su vez, especialmente éstos últimos, acabaran siendo considerados como una especie de mitos populares para la cultura urbana y cosmopolita, al reciclarse su valor socio cultural, y se convertirán en algo aceptable para la clase hegemónica (Szir, 2010: 464; Piñeiro y Sotolano, 2001: 263). Otro aspecto importante a tener en cuenta es que, al igual que el mismo paisaje visual, todos estos actores sociales participarán activamente en la construcción de una identidad nacional que por una parte mira hacia el progreso y el futuro, pero por otra aspira a reivindicar sus orígenes. 


\section{EL NACIONALISMO Y LA PRESERVACIÓN DE LA MEMORIA}

En el marco contextual del Centenario Argentino, Fortuny también será el gran ilustrador de los escenarios que conmemorarán acontecimientos históricos: los relativos a la conquista española de los indígenas, como acabamos de ver, la lucha por la independencia argentina o los conflictos con otros países latinoamericanos durante el siglo XIX. El Centenario Argentino, celebrado el 25 de mayo de 1910, homenajeaba la Revolución de Mayo de 1810. A raíz de ésta, se estableció el primer gobierno patrio argentino, al ser derrocado el virrey español Baltasar Hidalgo de Cisneros, y se declaró la independencia de las Provincias Unidas del Río de la Plata respecto a España (Vid: Gelman y Fradkin, 2010). Entre los diferentes festejos se encontraba la celebración de la Exposición Internacional del Centenario, que tuvo lugar entre los meses de mayo y noviem. bre de 1910.

Como ilustrador del pasado, Fortuny se dedicará sobre todo a recrear efemérides, tal como muestran las páginas de El Gladiador (1902-1905), Plus Ultra (1916-1930) o La Vida Moderna (1907-1912). En este último caso, llama la atención que una revista que ya en su mismo título destaca el concepto de modernidad, también dedique atención a las gestas del pasado. Con un estilo realista que lo aleja totalmente de la estética cultivada en las caricaturas, Fortuny relatará diversas batallas y numerosos sucesos históricos, que se enmarcan fuera de la ciudad, e incluso, hacen referencia a la lucha por la independencia de países vecinos, como Chile. Enumeraremos a continuación algunos pocos ejemplos: "Batalla de Maipo",34 que tuvo lugar el 5 de abril de 1818 cerca de Santiago de Chile; "La Batalla de Estero Bellaco - 2 de mayo de 1866",35 donde la llamada Triple Alianza -conformada por la República Argentina, el Emperador del Brasil y el Partido Colorado de la República Oriental del Uruguay- se enfrentó al ejército de Paraguay; o "12 de Enero de 1861 - Fusilamiento del Sr. Antonio Aberastain gobernador de San Juan", acaecido después de la batalla de Rinconada del Pocito. Algunas ilustraciones mostrarán sin embargo un enfoque plástico de carácter casi fotográfico, tal como vemos compositivamente en "El Combate de Aratá - 4 de mayo de 1868", ${ }^{36}$ donde se describe el ataque del ejército paraguayo contra las fuerzas argentinas y brasileñas, o sobre todo, en el "El Combate del Puente de Márquez - 26 de abril de 1829”, episodio relativo a la guerra civil argentina, donde el soldado montado a caballo en primer término aparece recortado, y toda la escena rebosa un extremo dinamismo (Fig. 6 ).

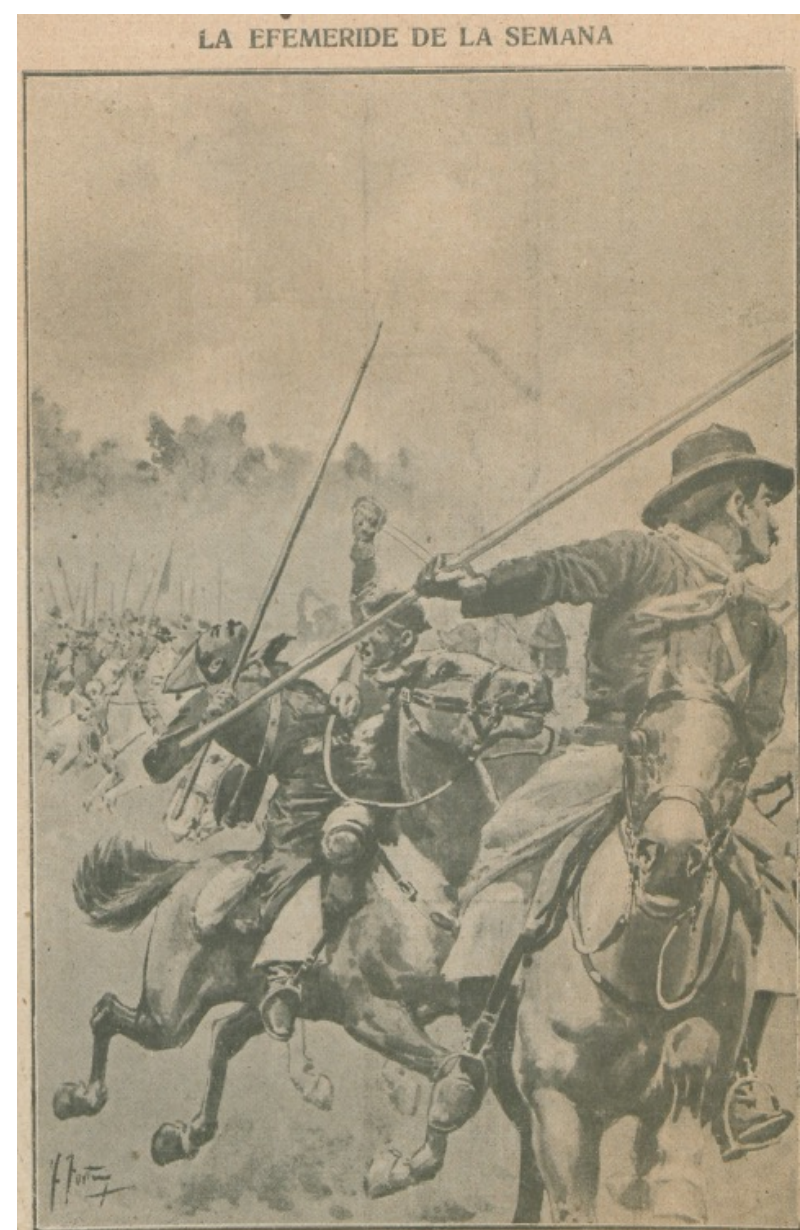

Fig. 6 / Fortuny, Francisco (23 de abril -1908). El Combate del Puente de Márquez - 26 de abril de 1829. Ilustración de La Vida Moderna, n. 54, 13

En la revista El Gladiador también encontramos numerosas efemérides ilustradas por Fortuny, especialmente durante el año 1904. En este caso, además, cabe añadir que aparecerán en forma de una especie de doble portada, en blanco y negro, en el interior de la publicación. La primera portada, a todo color, muy parecida por sus caricaturas al resto de semanarios satíricos y con una temática vinculada a la actualidad, contrastará con esta segunda, que se muestra mucho más conservadora a nivel estilístico en su recreación visual del pasado. ${ }^{37}$ Uno de los sucesos que allí ilustrará Fortuny será por ejemplo “15 de julio 1811, bombardeo de Buenos Aires por los buques realistas", ${ }^{38}$ o "18 de julio 1866, Combate del Boquerón (Guerra del Paraguay)" (Fig.7), entre muchos otros.

Como observamos en todas estas ilustraciones, otro de los objetivos de las publicaciones del momento, más allá de plasmar el progreso y las noticias de actualidad, era el de reconstruir y preservar la memoria. Y precisamente a los artífices de la prensa se les considerará los “forjadores de la patria” (Beltrán, 1943). Pero este anhelo de aspiraciones nacionalistas no se reflejará únicamente en las revistas o en los cuadros históricos, sino también, y muy especialmente, en los libros escolares, tarea en la cual, como hemos apuntado al principio, también colaque también aparecerá en revistas como: PBT, La Vida Moderna, Fray Mocho, El Hogar...(vid: Gutiérrez, 1997: 440).

38 Fortuny, F. (15 de julio -1904). Ilustración de El Gladiador, n. 137. 
borará prolíficamente Fortuny. ${ }^{39}$ Tanto en un caso como en otro, se trataba de "historiar", pero no a través de la mera compilación datos y fechas, sino a través de la recreación plástica de la visión del pasado. Se conseguía así estimular mucho mejor la memoria "para generar un sentimiento de amor a la Nación y así colaborar en la construcción del sentido histórico" (Mantovani y Villanueva, 2016: 190).

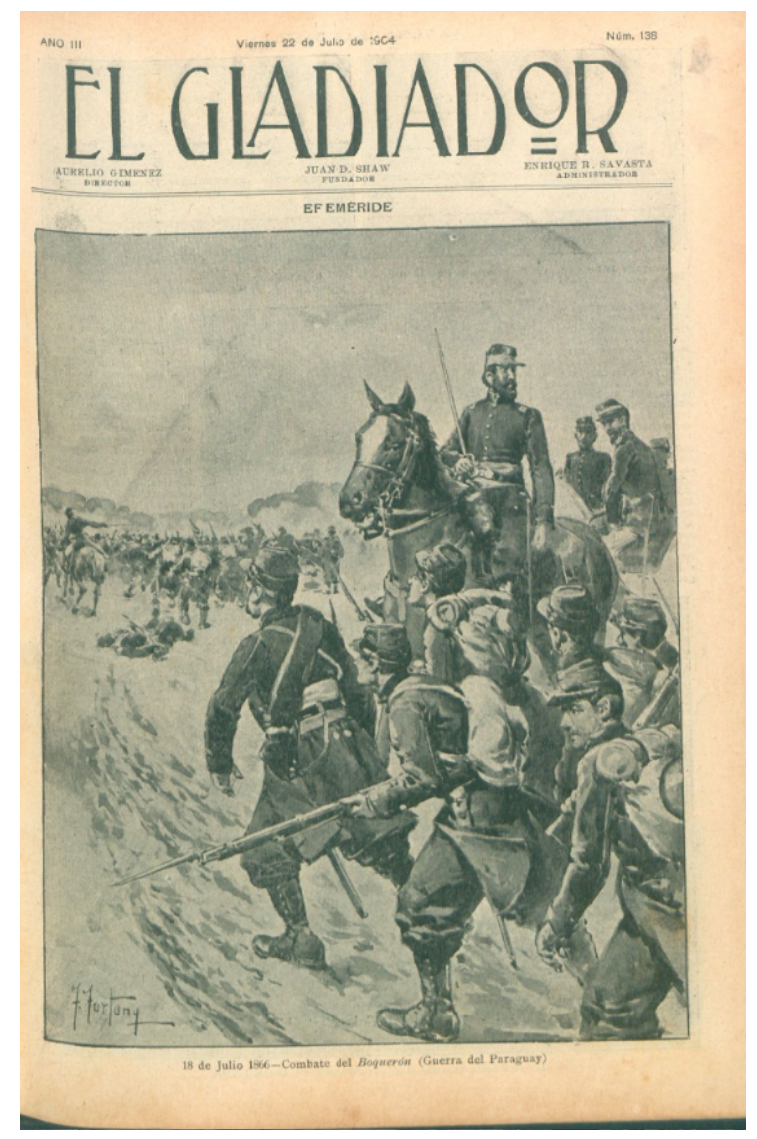

Fig. 7 / Francisco Fortuny (22 de julio -1904). 18 de julio 1866, Combate del Boquerón (Guerra del Paraguay). Ilustración de El Gladiador, n. 138.

Con estos relatos visuales se conseguía además unificar las distintas narraciones existentes y, en definitiva, contribuir a configurar didácticamente una iconografía nacional. Sin embargo, no hay que olvidar de que se trata de "reconstrucciones" visuales y que, por tanto, dichas imágenes vienen condicionadas por la interpretación realizada por su artífice. Pese a recurrir a documentos precisos para elaborar dichas recreaciones, lo cierto es que con frecuencia se presentaba una "recomposición transfigurada de esa misma realidad que se intentaba reproducir” (Gutiérrez, 1996: 6). El propio Fortuny se lamentaba, en una carta dirigida a Martiniano Leguizamón, de que los historiadores tenían "sus inclinaciones individuales" de manera que «la tan manoseada realidad se convierte en un tejido de diversos colores y de tramas completamente distintas; cada uno de los historiadores confecciona a su libre albedrío. Esta es la historia" (Fortuny, Carta del 28 de septiembre de 1933). ${ }^{40}$ Por ese motivo,

39 Resultaría interesante elaborar un estudio comparativo entre las diferentes obras de temática histórica de Fortuny, tanto en el campo de la pintura como el de la ilustración (de revistas y de textos escolares). Posiblemente comprobaríamos que el artista reutiliza algunas de esas imágenes en un ámbito u otro, dada su extensa e ingente producción. Sin embargo, dicha investigación se escapa de los límites de este artículo.

40

Andreeto, M. A. (1990). La correspondencia de Martiniano Leguizamón (segunda parte). Investigaciones y Ensayos, n. 40. Citado en: Gutiérrez , 1996: 13 como explica Gutiérrez, el artista catalán intentó concienciar al público y a los mismos historiadores de la necesidad de aplicar un mayor rigor histórico en este tipo de ejecuciones. El mismo Fortuny confesaba a Leguizamón que poseía un archivo con más de 3000 grabados que le permitían documentarse de manera fidedigna en cuestiones relativas a la vestimenta, los medios de locomoción, los edificios arquitectónicos... En definitiva, "su legado es invalorable. Resulta casi imposible dejar de lado sus reconstrucciones, cuando se quiere ilustrar de un modo vívido un texto sobre el pasado que atraiga al gran público" (Páez de la Torre, 2017).

Resulta importante relacionar este tipo de ilustraciones con la producción pictórica que Fortuny consagró al género histórico, pese que aquí nos resulte imposible profundizar en este último aspecto. Baste con destacar el encargo que recibió el artista catalán por parte de Enrique Udaondo, fundador del Museo Histórico de Luján, de elaborar una serie de cuadros históricos de la ciudad con una voluntad claramente pedagógica (vid: Blasco, 2009). Se trataba pues de moldear la consciencia histórica nacional a través de las imágenes, y de que por tanto éstas actuaran como un soporte visual que reforzara el guión museológico (Mallol, 2013: 9-12). Cuando Fortuny recibió dicho encargo, estaba ya trabajando en el Museo de Luján como restaurador - para ello fue contratado en 1925- de modo que en la década de los años veinte, Fortuny gozaba ya de una prestigiosa reputación (Blasco, 2009, p. 125 y 161).

Para acabar, querríamos señalar algunas observaciones relativos a los aspectos estéticos o formales de las ilustraciones de Fortuny. Durante toda su trayectoria, pese al paso de los años y el cambio estético manifestado en las propias revistas en las cuales participó - la mayoría evolucionaron del art nouveau al art déco- Fortuny se mantuvo fiel a un estilo de carácter realista, fácilmente identificable. Muchas de las ilustraciones se encuentran firmadas -con la expresión "F. Fortuny", prescindiendo pues del segundo apellido que sí encontrábamos en las revistas catalanas- pero aquellas que no lo están se pueden reconocer con facilidad...aunque no con total seguridad, ya que este tipo de estética era compartida por otros ilustradores, especialmente en el cultivo de temas históricos. Será especialmente en las caricaturas - más bien escasas en su amplia producción- donde consideramos que Fortuny se acerca más a la modernidad. 


\section{CONSIDERACIONES FINALES}

Cabría ahondar en los motivos por los cuales un español como Fortuny se acabó especializando en el tipo de iconografías impulsadoras del nacionalismo argentino. Según Aguerre, se trataba de "apaciguar y hermanar las relaciones entre ambas naciones" y de que España dejara de ser considerada una metrópoli tiránica (Aguerre, 2005: 52). Sin embargo, en la misma época nos detallan otros motivos. Santiago Maciel, escritor habitual de Caras y Caretas desde sus inicios, contaba que, estando aún al cargo como director de dicha revista José. S Álvarez -más conocido como Fray Mocho ${ }^{41}$ - éste se quejaba de que los ilustradores autóctonos no estaban interesados en tratar temas costumbristas o la incipiente "literatura nacional". Por el contrario, sus motivaciones se orientaban hacia temas más "trascendentes" y fantasiosos. Cuando el propio Maciel le presentó un texto para que fuera ilustrado, Fray Mocho se topó con serias dificultades. Como relata Maciel, “El dibujante asignado, nunca abordaba el asunto, unas veces por olvido y otras porque el decadentismo, ${ }^{42}$ a la sazón en auge, no armonizaba ni con los sobrios matices del panorama, ni con la indumentaria de los personajes, tan poco abundante en abigarrados tonos" (Maciel, 1917: 75). De manera que finalmente, como "venganza" - de ahí el título del artículo- Fray Mocho decidió encomendar la tarea a un español como Fortuny, que será quien acabará ilustrando el citado texto..$^{43} \mathrm{El}$ resultado acabó agradando a ambos, de manera que Fray Mocho decidió prescindir de los artistas nacionales y encargar este tipo de temática a artistas extranjeros que pudieran mostrar un mayor interés. Vemos pues que para dar respuesta a la cuestión planteada sería necesario tener en cuenta diversos factores, inclusive el mismo fenómeno de la inmigración que apuntábamos al inicio del artículo.

En relación a este aspecto cabe plantearse otra reflexión, a modo de síntesis. Dada su pronta emigración a Buenos Aires, en Cataluña Fortuny obtuvo bien poca consideración y a nivel historiográfico prácticamente ni se le menciona. En el ámbito español sí que ha recibido más atención, sobre todo en lo concerniente a los estudios sobre artistas españoles que emigraron a Buenos Aires (vid. Fernández-García, 1997 y Gutiérrez, 1997). La situación en Argentina, sin embargo, es diferente. Durante su trayectoria artística, Fortuny recibió numerosos encargos en diferentes ámbitos, como hemos visto. Fue pues un artista muy conocido, que gozó de gran prestigio. Por ese motivo, a nivel historiográfico, ha recibido mucha más atención que en su país de origen, especialmente en lo referente al proyecto pedagógico y nacionalista del Museo Histórico de Luján (vid. Mallol, 2013). No obstante, consideramos que, dada su extensísima, variada y prolífica producción, son necesarios todavía estudios que profundicen en su obra, centrándose en diferentes ámbitos, como por ejemplo el artículo que presentamos. Igualmente resultaría interesante un análisis que efectuara un recorrido por toda su obra en general, a fin de poder valorarla mejor en su conjunto. revista, desde 1898 hasta 1903, año de su fallecimiento.

42 El Decadentismo es un corriente artístico literario vinculado al movimiento Simbolista. Éste último se originó en París durante la década de los años 1870-1880 y de allí se expandió al resto de Europa y al continente americano. Efectivamente, como en muchos otros centros culturales, tales como Cataluña, en 1898 el Decadentismo se encontraba en pleno apogeo.

43 Fortuny, F. (3 de mayo- 1899). La Querencia. Ilustración de un texto de Santiago Maciel, Caras y Caretas, n. 32, 10-11. 
Aguerre, M. (2005). Lazos de bronce y mármol. En: Aznar, Y.; Wechsler, D. B., comps. La memoria compartida. España y la Argentina en la construcción de un imaginario cultural (1898-1950). Buenos Aires: Paidós, 49-76.

Artistas españoles (30 de abril, 1908). Papel y Tinta, n. 38, Buenos Aires, p. 3.

Beltrán, O. R. (1943). Historia del periodismo argentino. Pensamiento y obra de los forjadores de la patria. Buenos Aires: Editorial Sopena Argentina.

Blasco, M. E. (2009). El Museo Histórico y Colonial de la provincia de Buenos Aires (Luján), 1918-1938. Tesis doctoral. Universidad de Buenos Aires. Facultad de Filosofía y Letras.

Bonelli, A. (2017). Imagen impresa y ciudad, Buenos Aires (1890-1910), Inmediaciones de la comunicación, 12 (n. 12). Uruguay: Facultad de Comunicación y Diseño de la Universidad ORT Uruguay, 99-127.

Catálogo General ilustrado de la Primera Exposición de acuarelas, dibujos, pinturas al óleo y escultura celebrada por el Centro de Acuarelistas de Barcelona en el Museo Martorell (1885). Barcelona: Montaner y Simón Editores.

Cecchi, A. (2012). La timba como rito de pasaje: la narrativa del juego en la construcción de la modernidad porteña (Buenos Aires, 1900-1935). Buenos Aires: Teseso.

Daireaux , G. (1901). Tipos y paisajes criollos. Buenos Aires: Prudent Hnos. y Moetze.

D. Francisco Fortuny (31 de diciembre, 1964). La Nación. Buenos Aires.

Fernández-García, A. M. (1997). Arte y emigración: la pintura española en Buenos Aires, 1880-1930. Oviedo: Universidad de Oviedo.

Fernández, J. L.; López, C.; Petris, J. L. (1999). La ciudad y la prensa medios gráficos frente a las transformaciones de Buenos aires. En: Gutman, M.; Reese, T., eds. Buenos Aires 1910: el imaginario para una gran capital. Buenos Aires: Eudeba.

Francisco Fortuny (2004). En: lustradores de Caras y caretas. Sus dibujos originales. Buenos Aires: Biblioteca Nacional.

Garabedian, M. H. (2012). El correo español de Buenos Aires y la prensa española en el Río de la Plata. Nuevos enfoques para su estudio. História: Questões \& Debates, Curitiba, n. 56. Brasil: Universidade Federal do Paraná, 159-177.

Gelman, J.; Fradkin, R. (2010). Doscientos años pensando la Revolución de Mayo. Buenos Aires: Sudamericana.

Gesualdo, V. et al. (1969). Francisco Fortuny. En: Enciclopedia del arte en América. Buenos Aires: Omeba.

Gorelik, A. (2004). La grilla y el parque. Espacio público y cultura urbana en Buenos Aires, 1887-1936. Buenos Aires: Universidad Nacional de Quilmes.

Gutiérrez, R. (1996). La pintura de historia en la Argentina, Atrio, n. 8-9. Sevilla: Universidad Pablo de Olavide, 197-214.

Gutiérrez, R. (1997). Presencia de España en la Argentina. Dibujo, caricatura y humorismo (1870-1930). Cuadernos de Arte de la Universidad de Granada, n. 28, 113-124.

Gutman, M.; Reese, T. (eds.) (1999). Buenos Aires 1910. El imaginario para una gran capital. Buenos Aires: Editorial Universitaria de Buenos Aires.

Huguet, F. (9 de agosto-1956). Francisco Fortuny, el pintor de la historia argentina. Vea y Lea. Buenos Aires, 21-24.

Libro de bautismos de la Pobla de Montornès, 1872-1866.

Libro de Matrícula. Enseñanza Profesional de Dibujo, Pintura, Escultura y Grabado. Cursos de 1880-1881, 1881-1882, 1882-1883, Archivo de la Real Academia Catalana de Bellas Artes de San Jorge de Barcelona.

Maciel, S. (22 de diciembre-1917). La venganza de Fray Mocho. Caras y Caretas, n. 1003, 75.

Mallol, V. (2013). Pintura de historia. La producción de Francisco Fortuny. El programa de Enrique Udaondo para el Museo Histórico Colonial de Luján (1922-1930). Tesis de Maestría. Buenos Aires: Universidad Nacional de San Martín.

Malosetti, L. (2002). Los primeros modernos. Arte y sociedad en Buenos Aires. Buenos Aires: Fondo de Cultura Económica.

Nota Editorial (mayo-1894). Buenos Aires Ilustrado. 
Mantovani, L.; Villanueva, A. (2016). Libros escolares y enseñanza de la historia: el manual ilustrado Historia argentina de los niños en cuadros. En: Szir, S., coord., Ilustrar e imprimir. Una historia de la cultura gráfica en Buenos Aires, 1830-1930. Buenos Aires: 2016,181-211

Matassi, N. (2019). Compañía Sudamericana de Billetes de Banco S.A., IFINRA Instituto Federal de Investigadores Numismáticos de la República Argentina. Recuperado de: https://ifinra.org/2018/05/10/compania-sudamericana-de-billetes-de-banco-s-a/

Nostres grabats. Camí vell de la vall de Ribas (15 de octubre- 1886). La llustració Catalana, n.150. Barcelona, 386.

Ojeda, A. V.; Moya, J. E.; Sujatovich, L. (2018). Los nuevos magazines de principios del siglo XX en Argentina. En: Lima, H.; Reis, A. I.; Costa, P., coords. Comunicación y Espectáculo. Actas del XV Congreso de la Asociación de Historiadores de la Comunicación. Porto: Universidad do Porto. Reitoria, 426-444.

Otaegui (25 de octubre-1897). Nuestros colaboradores: Francisco Fortuny. Buenos Aires, n. 133,14 .

Páez de la Torre, C. (23 de julio- 2017). Pintó y dibujó el pasado argentino. Durante más de medio siglo, Francisco Fortuny dotó de imágenes a la historia nacional. La Gazeta. Recuperado de: https://www.lagaceta.com.ar/nota/738213/opinion/pinto-dibujo-pasado-argentino.html\%20\%20/

Piñeiro, P.; Sotolano, G. (2001). El Semanario Fray Mocho y lo popular. En: Historia de Revistas Argentinas, tomo IV. Buenos Aires: Asociación Argentina de Editores de Revistas.

Rigol, J. Catálogo del Palacio Nacional de Bellas Artes [Obra inédita]. La Habana: Museo Nacional de Bellas Artes de Cuba.

Rodríguez, A. E. (1982). Iconografía policial. Buenos Aires: Policia Federal Argentina.

Rodríguez-Molas, R. (1982). Historia social del gaucho. Buenos Aires: Centro Editor de América Latina.

Román, C. (2010). La prensa satírica Argentina del Siglo XIX: palabras e imágenes. Tesis doctoral, vol 1, Facultad de Filosofía y Letras, U.B.A. Recuperado de: repositorio.filo.uba.ar/jspui/bitstream/filodigital/.../1/uba_ffyl_t_2010_866245_v1.pdf

Szir, S. M. (2010). Figuraciones urbanas. Caras y Caretas, 1900. En: Lattes, Alfredo E., coord. Dinámica de una ciudad: Buenos Aires 1810-2010. Buenos Aires: Dirección General de Estadística y Censos.Gobierno de la Ciudad de Buenos Aires, 453-479.

Szir, S. M. (2014). El Sud Americano. Notas para una historia material y visual de la prensa periódica ilustrada en el siglo XIX. En: Delgado, V.; Mailhe, A.; Rogers, G., coords. Tramas impresas: Publicaciones periódicas argentinas (XIX-XX). La Plata: Universidad Nacional de La Plata. Facultad de Humanidades y Ciencias de la Educación, 80-97. Recuperado de: http://www.memoria.fahce.unlp.edu.ar/libros/ pm.376/pm.376.pdf

Szir, S. M. (6 de junio-2017). Imágenes y tecnologías entre Europa y la Argentina. Migraciones y apropiaciones de la prensa en el siglo XIX, Nuevo Mundo Mundos Nuevos. Imágenes, memorias y sonidos. Recuperado de: http://journals.openedition.org/ nuevomundo/70851; DOI: 10.4000/nuevomundo.70851 
